\title{
Estrogen Inhibits Colon Polyp Formation by Reducing Angiogenesis in a Carcinogen-Induced Rat Model
}

\author{
Jia Yang, ${ }^{1}$ Li-juan Xiong, ${ }^{2}$ Fei Xu, ${ }^{1}$ Xiang Zhao, ${ }^{1}$ Bo Liu, ${ }^{1}$ Kai-Lin Cai, ${ }^{1}$ and Guo-bin Wang ${ }^{1}$ \\ ${ }^{1}$ Department of Gastrointestinal Surgery, the Union Hospital of Tongji Medical college of Huazhong University of Science \& Technology, \\ Wuhan 430022, China \\ ${ }^{2}$ Department of Infectious Diseases, the Union Hospital of Tongji Medical college of Huazhong University of Science \& Technology, \\ Wuhan 430022, China
}

Correspondence should be addressed to Kai-Lin Cai; kailincai@163.com and Guo-bin Wang; wangguobinxiehe@163.com

Received 2 June 2013; Revised 11 September 2013; Accepted 22 September 2013

Academic Editor: Stephen L. Atkin

Copyright (C) 2013 Jia Yang et al. This is an open access article distributed under the Creative Commons Attribution License, which permits unrestricted use, distribution, and reproduction in any medium, provided the original work is properly cited.

Objective. To study the effects of estrogen on colon polyp formation, proliferation, and angiogenesis on a rat model of colon cancer induced by dimethylhydrazine (DMH). Methods. Thirty-six female ovariectomized (OVX) rats were randomly divided into 3 groups: (I) control group (administrated with vehicles weekly), (II) DMH group (administrated with DMH weekly), and (III) $\mathrm{DMH}+\mathrm{E}_{2}$ group (administrated with $\mathrm{DMH}$ and $17 \beta$-estradiol weekly). The incidence, volumes, and multiplicity of colon polyps in each group were evaluated. The microvessel density (MVD), the expressions of Proliferating Cell Nuclear Antigen (PCNA), and the expressions of HIF- $1 \alpha$ and VEGF in polyps were detected in each group. Results. Estrogen reduced the multiplicity, volumes, and the PCNA expressions of DMH-induced colon polyps. The MVD in DMH $+\mathrm{E}_{2}$ group was significantly lower than that in DMH group. Estrogen treatment decreased the HIF-1 $\alpha$ and VEGF expressions at both mRNA and protein level. Conclusion. Estrogen replacement was protective for ovariectomized rats from DMH-induced carcinogenesis, and one of the mechanisms for this was due to estrogen's inhibitive effects on blood vessel formation by downregulating VEGF and HIF-1 $\alpha$ expressions.

\section{Introduction}

Plenty of epidemiologic evidence demonstrated that estrogen might influence the incidence of colon cancer in women [1-3]. Colon cancer risk increased after menopause and decreased after hormone replacement treatment (HRT) [4]. Many hypotheses had been proposed and studied. Estrogen receptors were found in colon epithelium and the estrogen receptor beta was the dominant subtype [5]. On cell models, many studies had found that estrogen could affect the growth of cells originated from colon mucosa $[6,7]$. On an animal model of rats induced by $\mathrm{DMH}$, we have found that ovariectomy could promote colon tumor formation [8]. Since the angiogenesis was vital for tumorigenesis and the estrogen was a well-known vasoactive hormone, it was worth investigating whether estrogen could influence angiogenesis in the course of colon carcinogenesis.

There were several types of vasculation during carcinogenesis, including angiogenesis, vasculogenesi, and vasculogenic mimicry. In early stage of cancer, the main type of vessel formation was angiogenesis [9], triggered by proangiogenic factors [10]. Among the pro-angiogenic factors, VEGF was the essential factor in angiogenesis [11, 12]. In the present study, we studied the effects of estrogen on the microvessel density (MVD) and the expression of VEGF and its main upstream regulator HIF-1 $\alpha$.

\section{Material and Methods}

2.1. Chemicals and Reagents. DMH and $17 \beta$-estradiol were purchased from Sigma (St. Louis, MO).

2.2. Animals. Female Sprague-Dawley rats were purchased from the Animal Center of Tongji Medical College. Protocols for animal experimentation and maintenance were approved by the Animal Ethics Committee at our university and carried out in accordance with the institutional guidelines.

Thirty-six female rats (10 weeks of age) were housed in plastic cages (4 rats per cage) under standard laboratory 
TABle 1: Primer sequences of HIF-1 $\alpha$, VEGF-A, and GAPDH genes.

\begin{tabular}{lcc}
\hline Gene & Forward sequence & Reverse sequence \\
\hline HIF- $1 \alpha$ & CCTACTATGTCGCTTTCTTGG & GTTTCTGCTGCCTTGTATGGG \\
VEGF-A & CAGCTATTGCCGTCCAATGA & CCAGGGCTTCATCATTGCA \\
GAPDH & ACAGCAACAGGGTGGTGGAC & TTTGAGGGTGCAGCGAACTT \\
\hline
\end{tabular}

conditions $\left(21 \pm 1^{\circ} \mathrm{C}\right.$ temperature, $50 \pm 10 \%$ humidity, and $12 \mathrm{~h}$ of light time from 6 am to $6 \mathrm{pm}$ ) with normal food and tap water provided ad libitum. All rats were ovariectomized (OVX) at the age of 11 weeks. At the age of 12 weeks, these rats were randomly divided into 3 groups according to the following treatment: control group $(n=12), \mathrm{DMH}$ group $(n=12)$, and $\mathrm{DMH}+\mathrm{E}_{2}$ group $(n=12)$. In the control group, rats were subcutaneously and intraperitoneally administrated with vehicles once a week. In the DMH group, rats received intraperitoneal injections of DMH $(20 \mathrm{mg} / \mathrm{kg}$ body weight) $[13,14]$ once a week. In the $\mathrm{DMH}+\mathrm{E}_{2}$ group, rats received subcutaneous injections of $17 \beta$-estradiol (40 $\mu \mathrm{g} / \mathrm{kg}$ body weight and dissolved in camellia oil) [15] once a week, together with the weekly intraperitoneal injections of $\mathrm{DMH}(20 \mathrm{mg} / \mathrm{kg}$ body weight). The weekly drugs injection lasted for 16 weeks. Six weeks after the last injection, all the animals were sacrificed by an overdose injection of chloral hydrate $(600 \mathrm{mg} / \mathrm{kg}$ intraperitoneal injection).

2.3. Harvesting of Specimen. After sacrifice, the entire colorectums were collected and opened longitudinally and washed with PBS. Polyps were identified through visual macroscopic examination and later verified with histopathological examination. The location and number of all the polyps were recorded. The length $(L)$, width $(W)$, and height $(H)$ of each polyp were measured, and the volume of each polyp was calculated using the formula $V=L \times W \times H \times \pi / 6$. The polyps with the volume ranging from $50 \mathrm{~mm}^{3}$ to $70 \mathrm{~mm}^{3}$ were cut into halves. One portion of the polyp was stored at $-80^{\circ} \mathrm{C}$ for RT-PCR and Western blot, and the other half was fixed in $4 \%$ paraformaldehyde and embedded in paraffin block. The polyps with a volume of $<50 \mathrm{~mm}^{3}$ or $>70 \mathrm{~mm}^{3}$ were all fixed in $4 \%$ paraformaldehyde and embedded in paraffin block.

2.4. Histopathological Evaluation. Polyps were fixed in $4 \%$ paraformaldehyde and embedded in paraffin. Then the polyp samples were cut into $4 \mu \mathrm{m}$ sections using a microtome.

Sections were stained with hematoxylin and eosin $(\mathrm{H} \&$ E) and examined histologically in a blinded manner.

2.5. Immunohistochemistry and MVD Assessment. Sections $(4 \mu \mathrm{m})$ were cut from paraffin-embedded polyp samples and mounted on poly-L-lysine-coated slides. Immunohistochemical staining was performed using anti-CD34 antibody (BOSTER, China) and anti-PCNA antibody (Cell Signaling technology, USA) with the avidin-biotin-peroxidase complex (ABC) method. The proliferation rate was assessed by the PCNA index, defined as the percentage of PCNA-positive

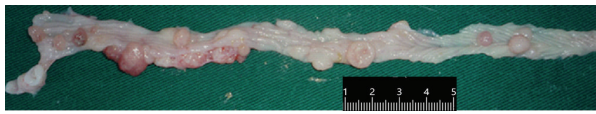

(a) $\mathrm{DMH}$

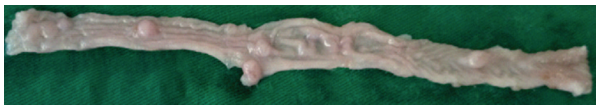

(b) $\mathrm{DMH}+\mathrm{E}_{2}$

FIgure 1: Polyps induced by DMH in experimental groups. (a) The polyps in $\mathrm{DMH}$ group. (b) The polyps in $\mathrm{DMH}+\mathrm{E}_{2}$ group.

cells. PCNA index was determined by counting PCNApositive cells in a total of at least 1000 cells in different randomly selected areas at $\times 400$ magnification. MVD was assessed by the method of Weidner [16]. The CD34-stained sections were initially scanned at low power $(\times 40$ and $\times 100)$ and the areas of specimens with the highest neovascularization stained by CD34 were selected as hot spots. Subsequently, microvessel counting was carried out in four fields of the hot spots at $\times 400$ magnification. Any brown-stained endothelial cells or cell cluster clearly separated from adjacent microvessels, tumour cells, and other connective tissue elements were considered as a single countable vessel. Red blood cell or vessel lumen was not necessary to define a microvessel.

2.6. Real-Time Quantitative RT-PCR. Tissue samples from the polyps ranging in volume from $50 \mathrm{~mm}^{3}$ to $70 \mathrm{~mm}^{3}$ and the normal colonic mucosa samples in the control group were used. Total tissue RNA was extracted with Trizol reagent (Invitrogen) following the manufacture's instruction. The cDNAs from total RNA were synthesized using PrimeScript RT reagent Kit (Takara, Japan). The mRNA expression was evaluated by real-time PCR with an ABI StepOne Plus (Applied Biosystems, Singapore). GAPDH was applied as the internal control. The concentrations of the reagents were adjusted to reach a final volume of $20 \mu \mathrm{L}$, containing $2 \mu \mathrm{L}$ cDNA product, $10 \mu \mathrm{L}$ SYBR Premix Ex Taq II (Takara, Japan), and $0.8 \mu \mathrm{L}$ of forward and reverse primers. The reaction was carried out by 45 amplification cycles of $95^{\circ} \mathrm{C}$ for $5 \mathrm{~s}$ and $60^{\circ} \mathrm{C}$ for $30 \mathrm{~s}$. PCR primers were designed by Primer 5.0 and Blast search to check specificity. Primer sequences used are listed in Table 1 . The results were calculated by $2^{-\Delta \Delta c t}$ method.

2.7. Western Blot. Tissue samples from the polyps ranging in volume from $50 \mathrm{~mm}^{3}$ to $70 \mathrm{~mm}^{3}$ and the normal colonic mucosa samples in the control group were used. Protein was extracted with protein extraction kit (Beyotime, China), 
TABLE 2: The incidence, multiplicity, average volume, and distribution of colon polyps.

\begin{tabular}{|c|c|c|c|c|c|c|}
\hline \multirow{2}{*}{ Group } & \multirow{2}{*}{ Amount of rats } & \multirow{2}{*}{ Incidence of polyps } & \multirow{2}{*}{ Polyp multiplicity } & \multirow{2}{*}{ Average volume } & \multicolumn{2}{|c|}{ Distribution of polyps } \\
\hline & & & & & Distal part & Proximal part \\
\hline Control & 12 & 0 & - & - & - & - \\
\hline $\mathrm{DMH}$ & 12 & $91.7 \%(11 / 12)$ & $6.8 \pm 3.1$ & $102.97 \pm 77.67$ & $82.9 \%(68 / 82)$ & $17.1 \%(14 / 82)$ \\
\hline $\mathrm{DMH}+\mathrm{E}_{2}$ & 12 & $66.7 \%(8 / 12)$ & $3.0 \pm 1.1^{*}$ & $45.85 \pm 43.40^{*}$ & $72.2 \%(26 / 36)$ & $27.8 \%(10 / 36)$ \\
\hline
\end{tabular}

${ }^{*} P<0.05$ compared with the DMH group.

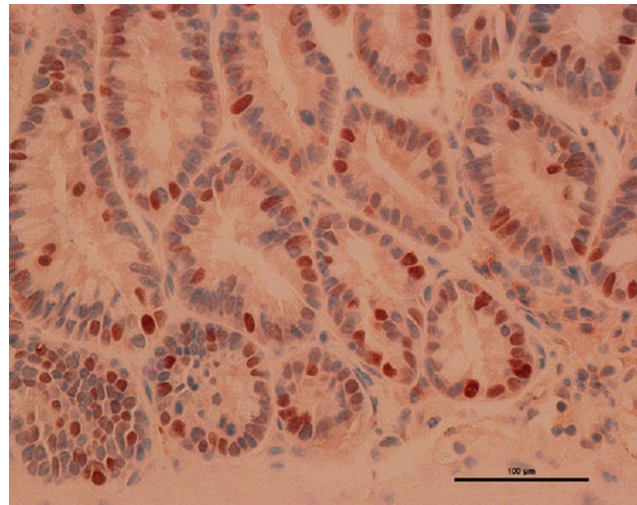

(a) $\mathrm{DMH}$

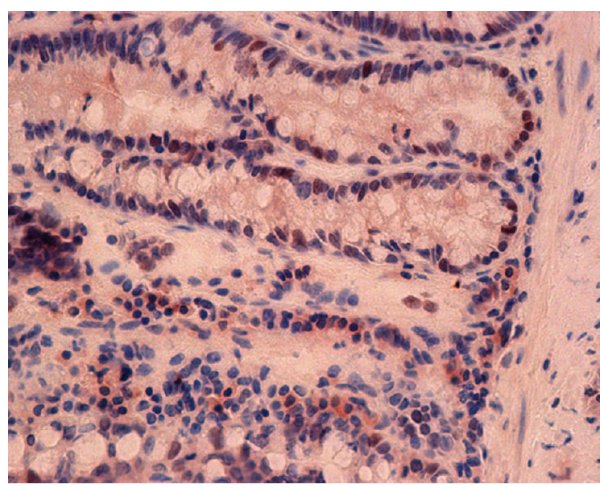

(c) Control

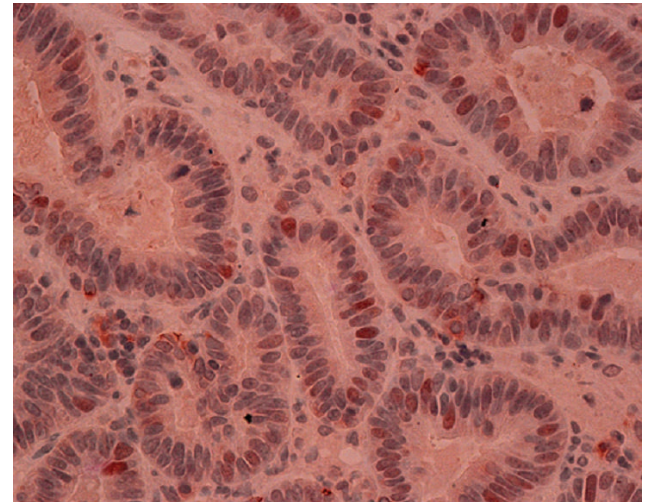

(b) $\mathrm{DMH}+\mathrm{E}_{2}$

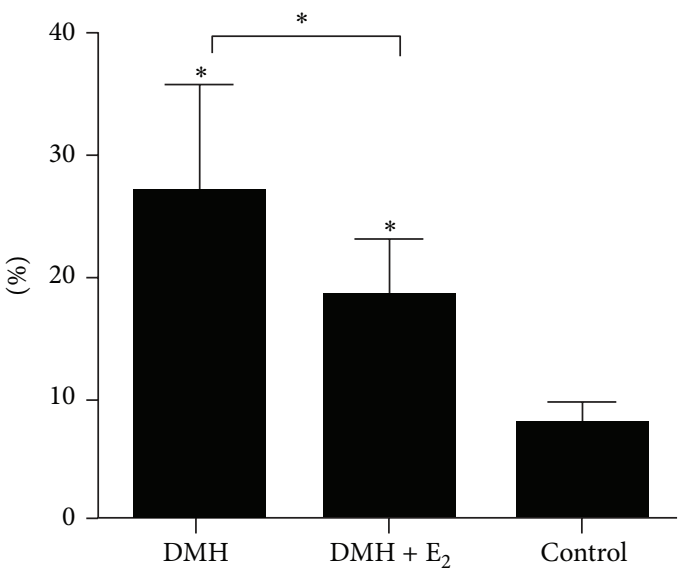

(d) PCNA index

FIGURE 2: PCNA expression in each group. (a) PCNA staining in polyp from the DMH group. (b) PCNA staining in polyp from the DMH $+\mathrm{E}_{2}$ group. (c) PCNA staining in normal colonic mucosa from the control group. (d) Comparison of PCNA index in different groups $\left({ }^{*} P<0.05\right)$.

separated on $10 \%$ SD-SPAGE, and transferred to polyvinylidene difluoride (PVDF) membranes (Millipore, USA). Membranes were blocked in 5\% nonfat milk diluted in TBST for 1 hour at room temperature and then were incubated overnight at $4^{\circ} \mathrm{C}$ with the following primary antibodies: antiHIF-1 $\alpha$ (Abcam, Cambridge, UK) and anti-VEGF-A (Abcam, Cambridge, UK). After rinsing with TBST for three times, the membrane was incubated with horseradish peroxidaseconjugated secondary antibodies for 1 hour at room temperature. The outcome was visualized by the ECL Plus Western blotting detection system according to the manufacturer's instructions.

2.8. Statistical Analysis. Results are expressed as mean \pm SEM. Data were evaluated by ANOVA in which multiple comparisons were performed using the least-significant difference method, while those data in heterogeneity of variance were analyzed by Kruskal-Wallis test. The volumes of polyps in the two experimental groups were evaluated by student's $t$ test. Colon polyp incidence was expressed as percentages, and results were statistically analyzed using the chi-square test. The differences were considered statistically significant at $P<0.05$. All analysis was tested with SPSS version 18.0.

\section{Results}

3.1. Estrogen Reduced the Multiplicity and Volumes of DMHInduced Polyps and the PCNA Index. Eleven out of 12 (91.7\%) rats in DMH group and 8 out of $12(66.7 \%)$ rats in $\mathrm{DMH}+\mathrm{E}_{2}$ group developed colon polyps (Figure 1), while none of the 


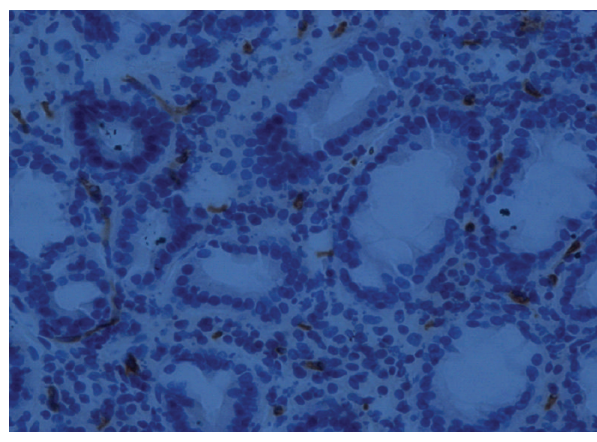

(a) $\mathrm{DMH}$

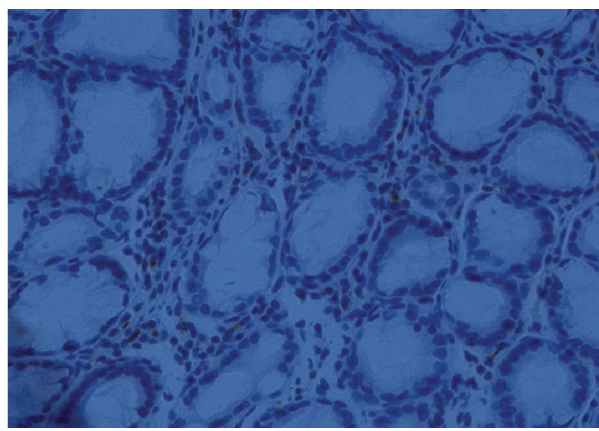

(c) Control

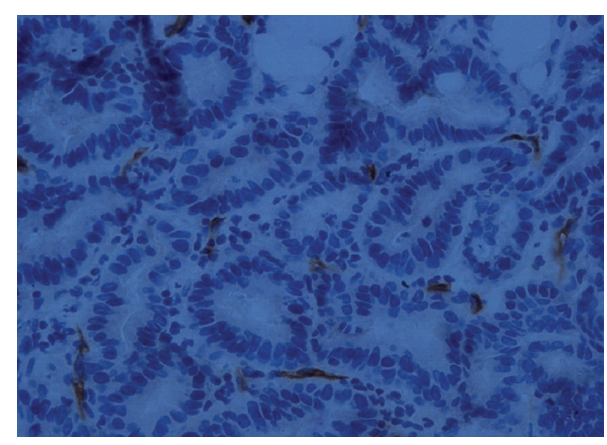

(b) $\mathrm{DMH}+\mathrm{E}_{2}$

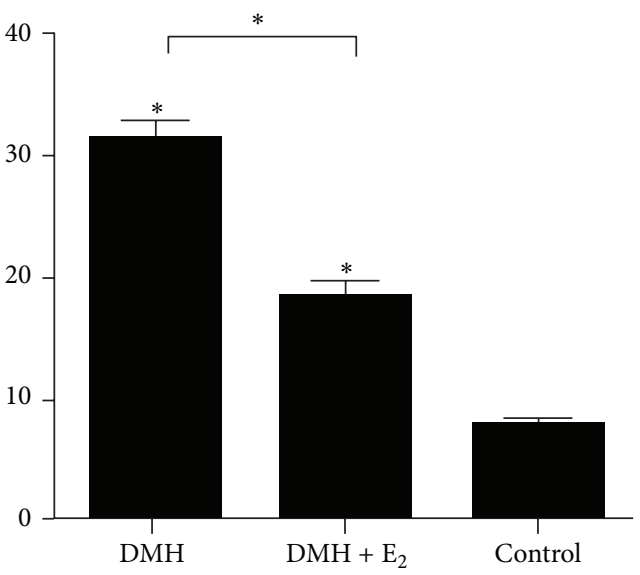

(d) MVD

FIGURE 3: The MVD in each group. (a) Representative CD34 staining in polyp from the DMH group ( $\times 400$ magnification). (b) Representative $\mathrm{CD} 34$ staining in polyp from the $\mathrm{DMH}+\mathrm{E}_{2}$ group. (c) Representative CD34 staining in normal colonic mucosa from the control group. (d) Comparison of MVD in different groups $\left({ }^{*} P<0.05\right)$.

rats in control group developed colon polyps. The incidence of colon polyps in DMH group was higher than that in $\mathrm{DMH}$ $+\mathrm{E}_{2}$ group (91.7\% versus $\left.66.7 \%\right)$, though this difference was not statistically significant $(P>0.05)$ (Table 2$)$. The polyp multiplicity (mean number of polyps per rat) in DMH group was significantly higher than that in $\mathrm{DMH}+\mathrm{E}_{2}$ group (6.8 \pm 3.1 versus $3.0 \pm 1.1, P<0.05$ ) (Table 2 ). The polyps were mainly distributed in the distal colon compared to the proximal counterpart. The outcome was coincident with the animal model as Tanaka described [17]. At the same time, the average volume of polyps in DMH group was significantly bigger than that in $\mathrm{DMH}+\mathrm{E}_{2}$ group $(102.97 \pm 77.67$ versus $45.85 \pm 43.40, P<0.05$ ) (Table 2).

The proliferation rates in different groups were assessed by the PCNA index. The PCNA index of the polyps from $\mathrm{DMH}$ group ranged from $19.6 \%$ to $31.2 \%$, with an average of $27.1 \% \pm 5.2 \%$. When $\mathrm{DMH}$ was administrated together with estradiol in $\mathrm{DMH}+\mathrm{E}_{2}$ group, the PCNA index decreased significantly to an average of $18.5 \% \pm 2.9 \%(27.1 \% \pm 5.2 \%$ versus $18.5 \% \pm 2.9 \%, P<0.05)$. The PCNA index in control group was significantly lower than that in the other two groups (Figure 2).

3.2. Estrogen Reduced the MVD in Polyps Induced by DMH. The MVD in control group was significantly lower than that in the other two groups (Figure 3). The MVD elevated to an average of $32.13 \pm 3.98$ per field in $\mathrm{DMH}$ group. When $\mathrm{DMH}$ was administrated together with estradiol, the MVD decreased to $19.0 \pm 4.24$ per field. The MVD in $\mathrm{DMH}+\mathrm{E}_{2}$ group was significantly lower than that in DMH group $(P<$ 0.05) (Figure 3).

\subsection{Estrogen Treatment Decreased the HIF-1 $\alpha$ and VEGF} Expressions at Both $m R N A$ and Protein Level. The mRNA expression of HIF- $1 \alpha$ in the $\mathrm{DMH}$ group or $\mathrm{DMH}+\mathrm{E}_{2}$ group was significantly upregulated compared to that of the control group (Figure 4(a)). And the mRNA transcripts in $\mathrm{DMH}$ group were almost 2-fold higher than that in $\mathrm{DMH}+\mathrm{E}_{2}$ group (Figure 4(a); $P<0.05$ ). We observed the similar tendency of HIF- $1 \alpha$ expression at protein level (Figure 4(c)).

VEGF expression in the $\mathrm{DMH}$ group or $\mathrm{DMH}+\mathrm{E}_{2}$ group was higher than that in control group at both mRNA (Figure 4(b)) and protein (Figure 4(c)) levels. When we compared $\mathrm{DMH}+\mathrm{E}_{2}$ group with $\mathrm{DMH}$ group, we found that estrogen treatment caused a significant decrease (1.43folds) in VEGF mRNA expression (Figure 4(b); $P<0.05$ ). The VEGF protein levels changed in the similar tendency (Figure 4(c)). 


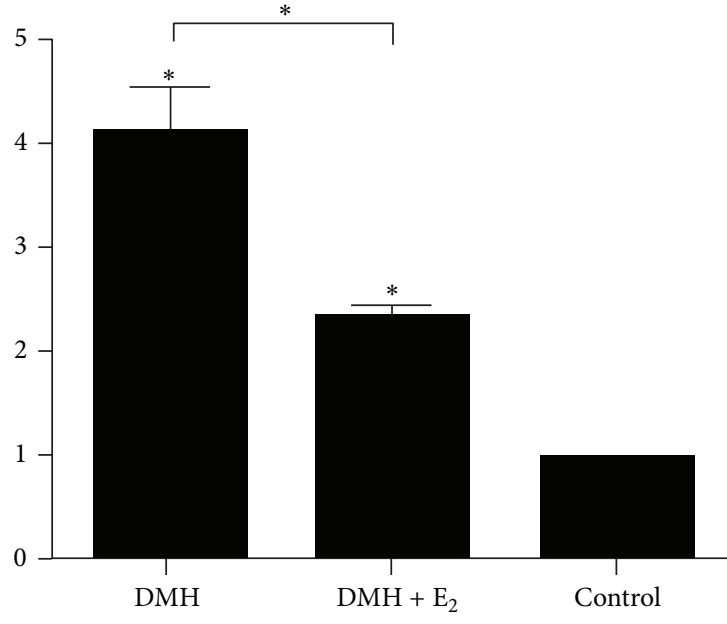

(a) HIF- $1 \alpha$ mRNA

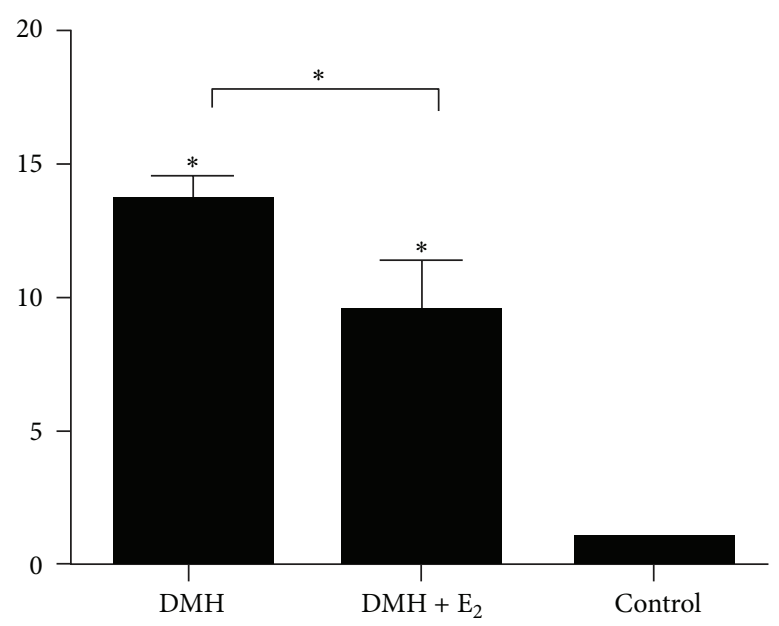

(b) VEGF-A mRNA

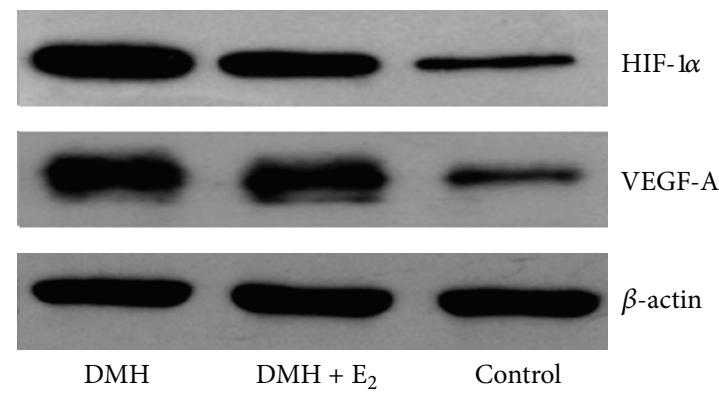

(c) Protein expression

FiguRE 4: Expressions of HIF-1 $\alpha$ and VEGF at mRNA and protein level. (a) Comparison of HIF-1 $\alpha$ mRNA level in different groups ( ${ }^{*} P<0.05$ ). (b) Comparison of VEGF-A mRNA level in different groups $\left({ }^{*} \mathrm{P}<0.05\right)$. (c) Representative immunoblot analysis of HIF-1 $\alpha$ and VEGF-A protein expressions in each group.

\section{Discussion}

Epidemical studies showed that postmenopausal women were at increased risk of colorectal cancer (CRC) compared with premenopausal women, and data from prospective randomized trials showed that HRT reduced the risk of CRC in postmenopausal women by 30 to $40 \%$ [18]. Many studies indicated that estrogen could inhibit proliferation and induce apoptosis in colon cancer cells $[19,20]$. However, the study of estrogen on tumorigenesis of colon cancer in animal models was scarce. In the present study, we investigated the effect of estrogen on colon polyp formation in an ovariectomized rat model. As a result, we found that the multiplicity and volumes of polyps in the estrogen-DMH simultaneous treated group were lower than those in the $\mathrm{DMH}$ treated group. This result confirmed that estrogen could inhibit colon carcinogenesis in $\mathrm{DMH}$-induced rat colon cancer model. And this result was accordant with the epidemiological results and the results found in colon cell models.

In our study, we found that the PCNA index of polyps in $\mathrm{DMH}+\mathrm{E}_{2}$ group was significantly lower than that in DMH group. This result suggested estrogen could inhibit tumor formation by inhibiting the proliferation ability of colon stimulated by the carcinogen. This result was also in agreement with the findings in the cell model [19] which indicated estrogen could inhibit the proliferation of colon cancer cell. Many studies had demonstrated that estrogen could negatively regulate cellular proliferation by estrogen receptor beta in several types of cancers, such as ovarian cancer and prostate cancer $[21,22]$. As estrogen receptor beta was the dominant estrogen receptor subtype in the colon tissue of rats [5], it was possible that estrogen might exert its antiproliferative effect by estrogen receptor beta in rats.

For the growth of tumor, increased proliferation must be accompanied by increased blood supply and this is achieved by angiogenesis and increased blood microvessel density [23]. Tumor angiogenesis is regulated by various activating and suppressive factors. Among the activating factors, VEGF plays a central role in the induction of angiogenesis. As an important transcription factor, HIF- $1 \alpha$ could mediate the induction of VEGF expression. Estrogen played important roles in angiogenesis in healthy or pathological conditions. During menstrual cycle, estrogen stimulates angiogenesis in the uterine endometrium. While in breast cancer, estrogen was found to induce the expression of VEGF [24]. However, the effects of estrogen on angiogenesis or proangiogenic factors were distinct in different conditions. And the difference might be related to the different predominant subtype of 
estrogen receptors expressed in the tissues. For example, estrogen could induce the expression of VEGF and activation of HIF- $1 \alpha$ in uterus mainly expressing estrogen receptor $\alpha$ [25], but estrogen inhibited angiogenesis and reduced the expression of VEGF in breast cancer which mainly expressed estrogen receptor beta [23]. In another study in prostate cancer [26], ER beta was reported to repress the transcription of VEGF and destabilize HIF- $1 \alpha$. These studies suggested that estrogen could inhibit angiogenesis and depress proangiogenic factors by ER beta. In our study, we found estrogen significantly depressed the microvessel densities in DMHinduced colon polyps. Accordingly, our study indicated that estrogen reduced the expression of VEGF and HIF-1 $\alpha$ in DMH-induced colon polyps. As ER beta was also the predominant ER subtype in the colon of rats, we hypothesized that estrogen might inhibit angiogenesis of colon polyps by downregulating HIF- $1 \alpha$ and VEGF via ER beta.

In summary, the present study demonstrated that estrogen could inhibit colon polyp formation in a rat model of colon cancer induced by DMH. Meanwhile, estrogen depressed the microvessel densities and reduced the expression of VEGF and HIF- $1 \alpha$. We supposed that estrogen might inhibit colon carcinogenesis by downregulating HIF- $1 \alpha$ and VEGF, eventually reducing angiogenesis.

\section{Authors' Contribution}

Jia Yang and Li-juan Xiong contributed equally to this work.

\section{Conflict of Interests}

The authors have no conflict of interests to disclose.

\section{Acknowledgment}

This study was supported by Grant (81272655) from the Natural Science Foundation of China.

\section{References}

[1] F. Al-Azzawi and M. Wahab, "Estrogen and colon cancer: current issues," Climacteric, vol. 5, no. 1, pp. 3-14, 2002.

[2] L. A. Ries, P. A. Wingo, D. S. Miller et al., "The annual report to the nation on the status of cancer, with a special section on colorectal cancer," Cancer, vol. 88, no. 10, pp. 398-424, 1997.

[3] J. J. DeCosse, S. S. Ngoi, J. S. Jacobson, and W. J. Cennerazzo, "Gender and colorectal cancer," European Journal of Cancer Prevention, vol. 2, no. 2, pp. 105-115, 1993.

[4] F. Grodstein, P. A. Newcomb, and M. J. Stampfer, "Postmenopausal hormone therapy and the risk of colorectal cancer: a review and meta-analysis," American Journal of Medicine, vol. 106, no. 5, pp. 574-582, 1999.

[5] J. Raju, A. Bielecki, D. Caldwell et al., "Soy isoflavones modulate azoxymethane-induced rat colon carcinogenesis exposed preand postnatally and inhibit growth of DLD-1 human colon adenocarcinoma cells by increasing the expression of estrogen receptor- $\beta$," Journal of Nutrition, vol. 139, no. 3, pp. 474-481, 2009.
[6] H. R. Wilkins, K. Doucet, V. Duke, A. Morra, and N. Johnson, "Estrogen prevents sustained COLO-205 human colon cancer cell growth by inducing apoptosis, decreasing c-myb protein, and decreasing transcription of the anti-apoptotic protein bcl2," Tumor Biology, vol. 31, no. 1, pp. 16-22, 2010.

[7] C. C. Weige, K. F. Allred, and C. D. Allred, "Estradiol alters cell growth in nonmalignant colonocytes and reduces the formation of preneoplastic lesions in the colon," Cancer Research, vol. 69, no. 23, pp. 9118-9124, 2009.

[8] F. Xu, G. Wang, K. Cai, R. Zhai, and S. Tang, "Effects of ovariectomy on microsatellite instability in rat colon tumors induced by 1,2-dimethylhydrazine," Molecular Biology Reports, vol. 37, no. 3, pp. 1397-1401, 2010.

[9] P. Carmeliet, "Angiogenesis in life, disease and medicine," Nature, vol. 438, no. 7070, pp. 932-936, 2005.

[10] G. N. Naumov, L. A. Akslen, and J. Folkman, "Role of angiogenesis in human tumor dormancy: animal models of the angiogenic switch," Cell Cycle, vol. 5, no. 16, pp. 1779-1787, 2006.

[11] F. Shojaei and N. Ferrara, "Antiangiogenic therapy for cancer: an update," Cancer Journal, vol. 13, no. 6, pp. 345-348, 2007.

[12] N. Ferrara, "Vascular endothelial growth factor: basic science and clinical progress," Endocrine Reviews, vol. 25, no. 4, pp. 581611, 2004.

[13] T. Ertekin, N. Ekinci, O. Karaca et al., "Effect of angiostatin on 1, 2-dimethylhydrazine-induced colon cancer in mice," Toxicol Ind Health, vol. 29, no. 6, pp. 490-497, 2012.

[14] N. Thurnherr, E. E. Deschner, E. H. Stonehill, and M. Lipkin, "Induction of adenocarcinomas of the colon in mice by weekly injections of 1,2-dimethylhydrazine," Cancer Research, vol. 33, no. 5, pp. 940-945, 1973.

[15] P. Smirnoff, Y. Liel, J. Gnainsky, S. Shany, and B. Schwartz, “The protective effect of estrogen against chemically induced murine colon carcinogenesis is associated with decreased $\mathrm{CpG}$ island methylation and increased mRNA and protein expression of the colonie vitamin D receptor," Oncology Research, vol. 11, no. 6, pp. 255-264, 1999.

[16] N. Weidner, J. P. Semple, W. R. Welch, and J. Folkman, “Tumor angiogenesis and metastasis-correlation in invasive breast carcinoma," The New England Journal of Medicine, vol. 324, no. 1, pp. 1-8, 1991.

[17] D. W. Rosenberg, C. Giardina, and T. Tanaka, "Mouse models for the study of colon carcinogenesis," Carcinogenesis, vol. 30, no. 2, pp. 183-196, 2009.

[18] R. T. Chlebowski, J. Wactawski-Wende, C. Ritenbaugh et al., "Estrogen plus progestin and colorectal cancer in postmenopausal women," The New England Journal of Medicine, vol. 350, no. 10, pp. 991-1004, 2004.

[19] V. Martineti, L. Picariello, I. Tognarini et al., "ER $\beta$ is a potent inhibitor of cell proliferation in the HCT8 human colon cancer cell line through regulation of cell cycle components," Endocrine-Related Cancer, vol. 12, no. 2, pp. 455-469, 2005.

[20] Y. Qiu, C. E. Waters, A. E. Lewis, M. J. S. Langman, and M. C. Eggo, "Oestrogen-induced apoptosis in colonocytes expressing oestrogen receptor $\beta$," Journal of Endocrinology, vol. 174, no. 3, pp. 369-377, 2002.

[21] J. Cheng, E. J. Lee, L. D. Madison, and G. Lazennec, "Expression of estrogen receptor $\beta$ in prostate carcinoma cells inhibits invasion and proliferation and triggers apoptosis," FEBS Letters, vol. 566, no. 1-3, pp. 169-172, 2004.

[22] O. Treeck, G. Pfeiler, D. Mitter, C. Lattrich, G. Piendl, and O. Ortmann, "Estrogen receptor $\beta 1$ exerts antitumoral effects on 
SK-OV-3 ovarian cancer cells," Journal of Endocrinology, vol. 193, no. 3, pp. 421-433, 2007.

[23] J. Hartman, K. Lindberg, A. Morani, J. Inzunza, A. Ström, and J.-Å. Gustafsson, "Estrogen receptor $\beta$ inhibits angiogenesis and growth of T47D breast cancer xenografts," Cancer Research, vol. 66, no. 23, pp. 11207-11213, 2006.

[24] J. Nakamura, A. Savinov, Q. Lu, and A. Brodie, "Estrogen regulates vascular endothelial growth/permeability factor expression in 7,12-dimethylbenz(a)anthracene-induced rat mammary tumors," Endocrinology, vol. 137, no. 12, pp. 5589-5596, 1996.

[25] A. A. Kazi and R. D. Koos, "Estrogen-induced activation of hypoxia-inducible factor- $1 \alpha$, vascular endothelial growth factor expression, and edema in the uterus are mediated by the phosphatidylinositol 3-kinase/Akt pathway," Endocrinology, vol. 148, no. 5, pp. 2363-2374, 2007.

[26] P. Mak, I. Leav, B. Pursell et al., "ER $\beta$ impedes prostate cancer EMT by destabilizing HIF- $1 \alpha$ and inhibiting VEGF-mediated snail nuclear localization: implications for gleason grading," Cancer Cell, vol. 17, no. 4, pp. 319-332, 2010. 


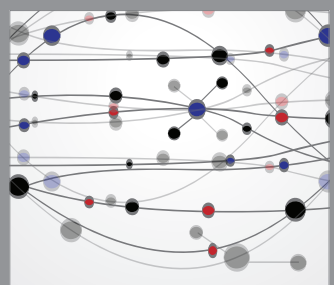

The Scientific World Journal
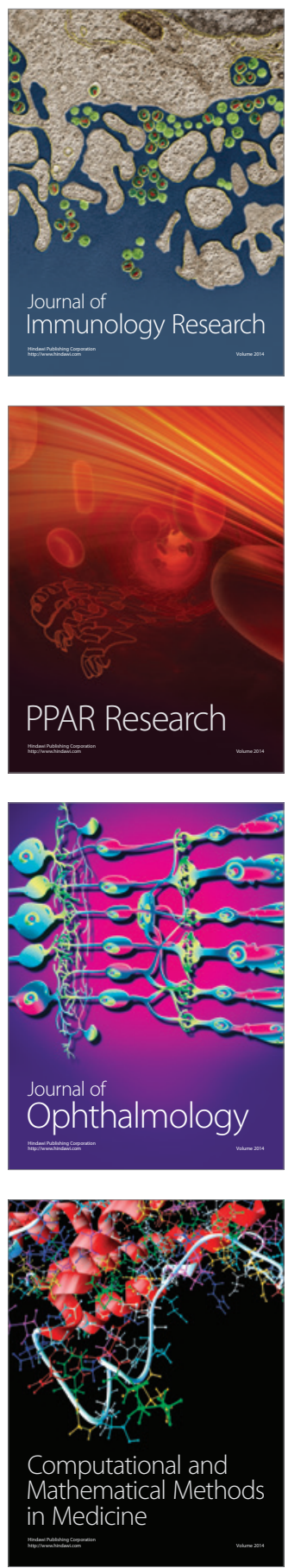

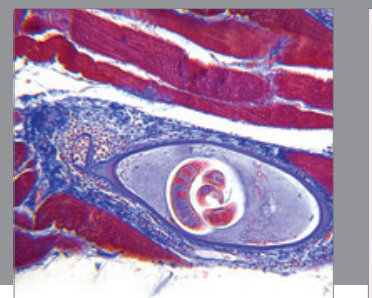

Gastroenterology

Research and Practice
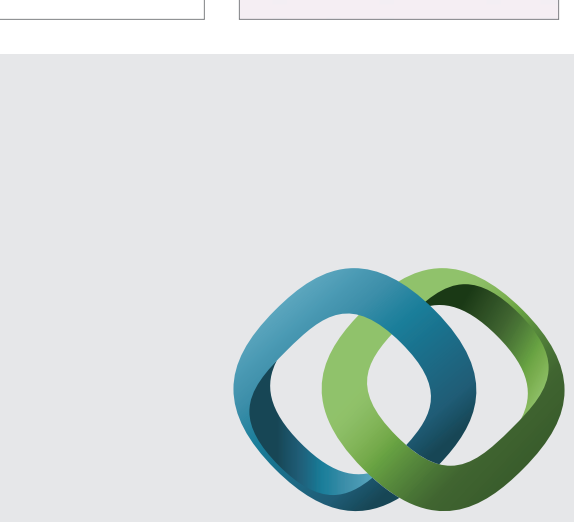

\section{Hindawi}

Submit your manuscripts at

http://www.hindawi.com
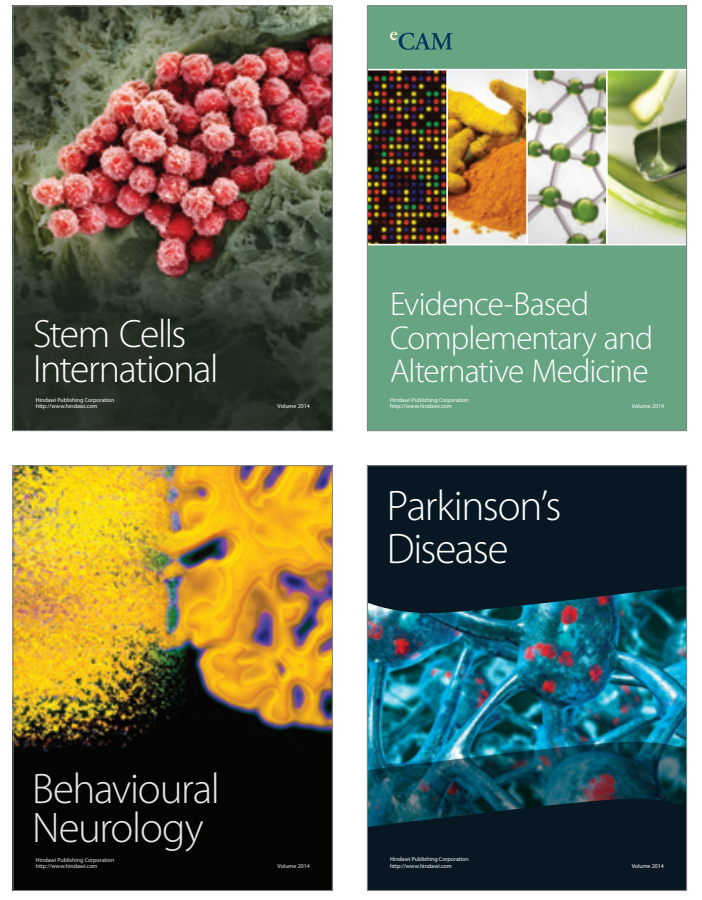
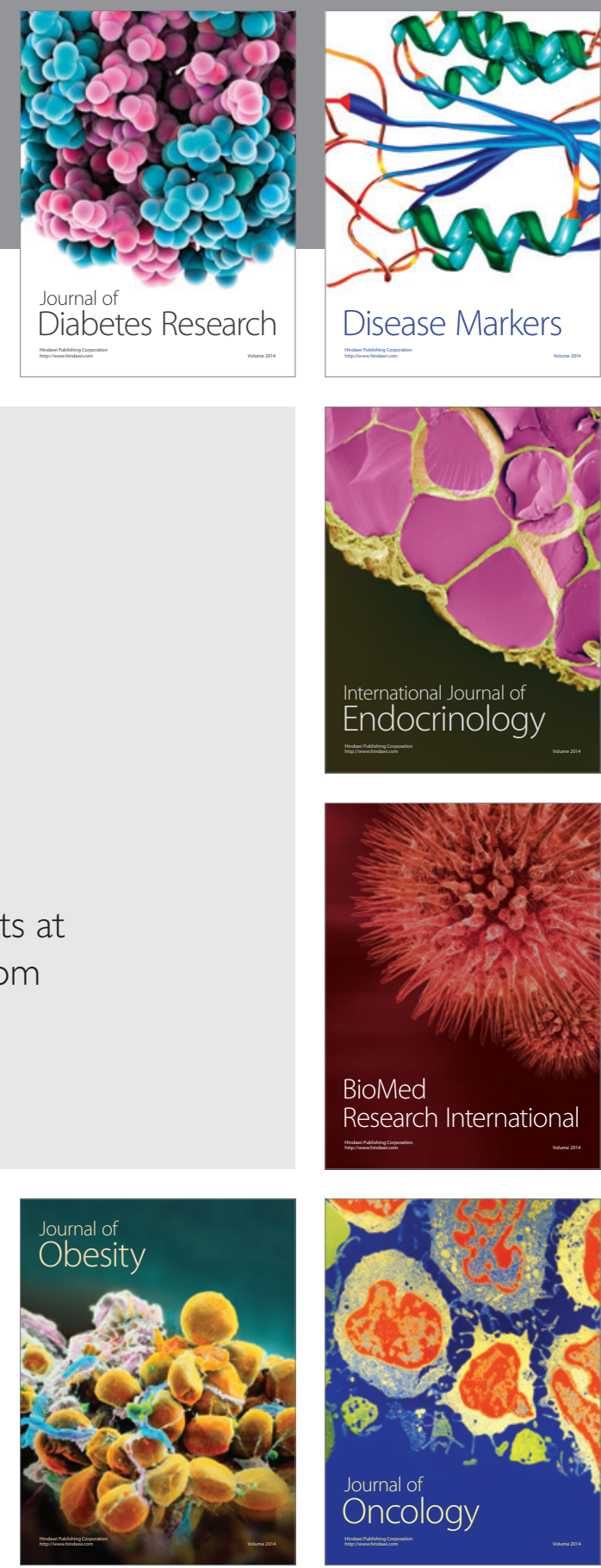

Disease Markers
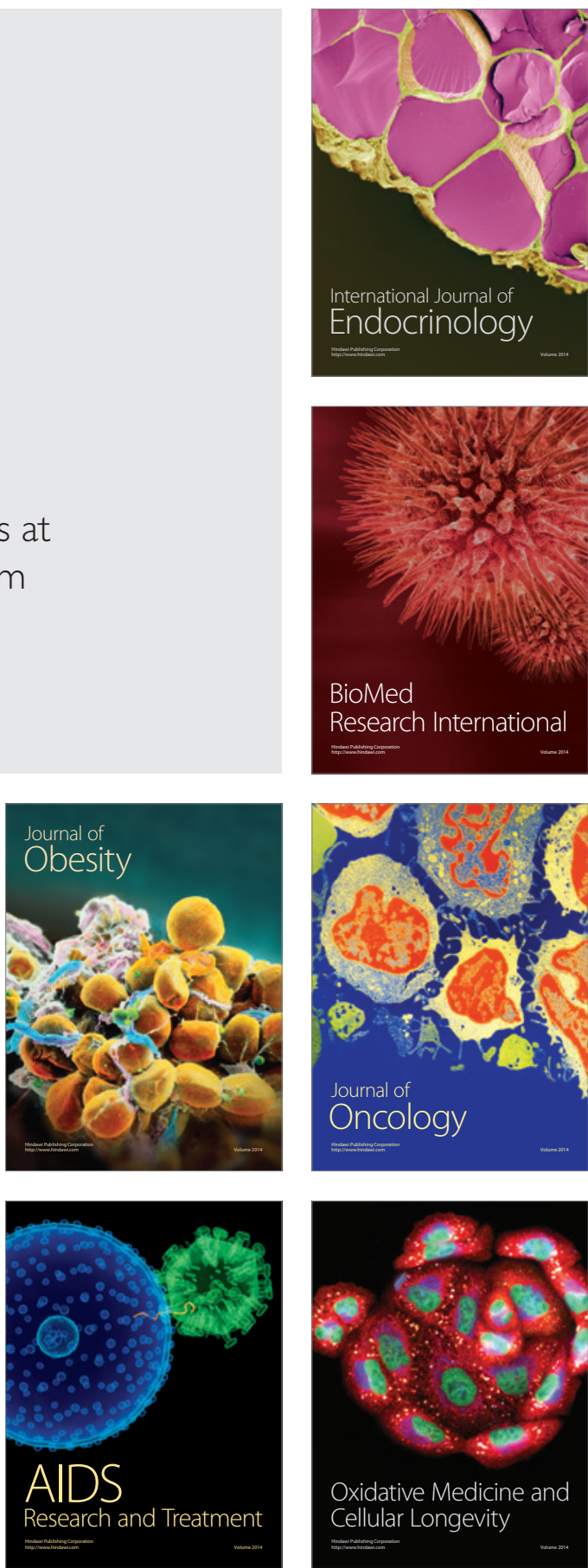